\title{
Cardiovascular risk and bipolar disorder: factors associated with a positive coronary calcium score in patients with bipolar disorder type 1
}

\author{
Aline R. Wageck, ${ }^{1,2}$ Felipe S. Torres, ${ }^{3,4}$ Clarissa S. Gama, ${ }^{1,2}$ Dayane S. Martins, ${ }^{1}$ Ellen Scotton, ${ }^{1}$ \\ Ramiro Reckziegel, ${ }^{1}$ Monise Costanzi, ${ }^{1,2}$ Regis G. Rosa, ${ }^{5}$ Flávio Kapczinski, ${ }^{1,6}$ Maurício Kunz ${ }^{1,2}$ \\ ${ }^{1}$ Programa de Transtorno Bipolar, Laboratório de Psiquiatria Molecular, Instituto Nacional de Ciência e Tecnologia Translacional em Medicina \\ (INCT-TM), Hospital de Clínicas de Porto Alegre (HCPA), Universidade Federal do Rio Grande do Sul (UFRGS), Porto Alegre, RS, Brazil. \\ ${ }^{2}$ Programa de Pós-Graduação em Psiquiatria e Ciências do Comportamento, UFRGS, Porto Alegre, RS, Brazil. ${ }^{3}$ Serviço de Radiologia, \\ HCPA, Porto Alegre, RS, Brazil. ${ }^{4}$ Programa de Pós-Graduação em Ciências Cardiovasculares, Faculdade de Medicina, UFRGS, Porto Alegre, \\ RS, Brazil. ${ }^{5}$ Departamento de Cuidados Intensivos, Hospital Moinhos de Vento e Hospital Mãe de Deus, Porto Alegre, RS, Brazil. \\ ${ }^{6}$ Department of Psychiatry and Behavioral Neurosciences, McMaster University, Hamilton, Canada.
}

\begin{abstract}
Objective: Cardiovascular disease is the leading cause of death in patients with bipolar disorder. The aim of this study was to evaluate the factors associated with positive coronary calcium score (CCS) in individuals with bipolar disorder type 1.

Methods: Patients from the Bipolar Disorder Program at Hospital de Clínicas de Porto Alegre, Brazil, underwent computed tomography scanning for calcium score measurement. Clinical and sociodemographic variables were compared between patients according to their CCS status: negative $(C C S=0)$ or positive (CCS $>0)$. Poisson regression analysis was used to examine the association of CCS with number of psychiatric hospitalizations.

Results: Out of 41 patients evaluated, only 10 had a positive CCS. Individuals in the CCS-positive group were older $(55.2 \pm 4.2$ vs. $43.1 \pm 10.0$ years; $p=0.001)$ and had more psychiatric hospitalizations $(4.7 \pm 3.0$ vs. $2.6 \pm 2.5 ; p=0.04)$ when compared with CCS- negative subjects. The number of previous psychiatric hospitalizations correlated positively with CCS $(p<0.001)$.

Conclusion: Age and number of psychiatric hospitalizations were significantly associated with higher CCS, which might be a potential method for diagnosis and stratification of cardiovascular disease in bipolar patients. There is a need for increased awareness of risk assessment in this population.
\end{abstract}

Keywords: Bipolar disorder; cardiovascular diseases; diagnostic techniques; cardiovascular; coronary disease

\section{Introduction}

Bipolar disorder (BD) is a chronic and disabling condition associated with a pro-inflammatory systemic status ${ }^{1-3}$ and is considered the fourth leading cause of disability-adjusted life years (DALYs) worldwide. ${ }^{4}$ In comparison to the general population, individuals with BD are particularly prone to multiple metabolic conditions. ${ }^{5}$ Cardiovascular disease is the leading cause of death in this population, with a standardized mortality ratio of 1.5 to $2.5^{6,7}$ In the U.S., individuals with $\mathrm{BD}$ have a five-fold increased risk of cardiovascular disease and manifest it 14 years earlier than adults without mood disorders. ${ }^{8,9}$

Complex mechanisms and multiple variables are part of the process that culminates with this increase in cardiovascular risk (CVR), including behavioral patterns and

Correspondence: Aline André Rodrigues Wageck, Laboratório de Psiquiatria Molecular, Instituto Nacional de Ciência e Tecnologia Translacional em Medicina (INCT-TM), Hospital de Clínicas de Porto Alegre, Universidade Federal do Rio Grande do Sul, Rua Ramiro Barcelos, 2350, CEP 90035-903, Porto Alegre, RS, Brazil. E-mail: aline.aarodrigues@gmail.com

Submitted Feb 13 2017, accepted Jun 13 2017, Epub Oct 022017. genetics. ${ }^{10}$ Several established CVR factors are more prevalent in individuals with $\mathrm{BD}$, including dyslipidemia ${ }^{11}$ hypertension, ${ }^{12}$ obesity, ${ }^{13,14}$ metabolic syndrome, ${ }^{15,16}$ and diabetes. ${ }^{12,17}$ Higher rates of cigarette smoking, ${ }^{18}$ a sedentary lifestyle, and poor dietary habits ${ }^{19}$ are also often observed. In addition, inflammatory and neuro-humoral abnormalities, such as hypothalamic-pituitary-adrenal axis and sympathetic hyperactivity, vascular inflammation, endothelial dysfunction, and oxidative stress, may also contribute to at least some of the pathophysiological mechanisms linked to increased CVR. ${ }^{20}$

Patients with severe mental illness are often excluded from screening and monitoring guidelines for cardiovascular disease, since they are part of a specific group that does not match the typical patient included in the large cohort or population-based studies of CVR stratification; they are younger, tend to have higher blood pressure, and are more likely to be smokers. ${ }^{21-24}$ Recently, BD among youth was one of the psychiatric conditions included in the moderate-risk category recognized as a condition that predisposes to accelerated atherosclerosis and, consequently, early cardiovascular disease. ${ }^{20}$ For the general population, the American Heart Association (AHA)/American 
College of Cardiology (ACC) Guideline on the Assessment of Cardiovascular Risk ${ }^{25}$ recommends the use of race- and sex-specific pooled cohort equations to predict 10 -year risk of first hard atherosclerotic cardiovascular event. If, after quantitative risk assessment, a risk-based treatment decision is uncertain, an additional evaluation, such as with coronary calcium score (CCS), may be considered to inform treatment decision making.

CCS, a direct and noninvasive measure of coronary atherosclerosis, is an independent and strong predictor of cardiovascular events and all-cause mortality ${ }^{26-28}$ and provides strong prognostic information above and beyond clinical risk scoring methods. ${ }^{29}$ However, it is not known whether CCS would be able to identify CVR in individuals with $\mathrm{BD}$ as well as in the general population, nor whether specific factors predict positive calcium scores in this population.

Within this context, the aim of the present study was to evaluate the factors associated with positive CCS in individuals with bipolar I disorder.

\section{Methods}

\section{Subjects}

This study is a cross-sectional analysis of outpatients with bipolar I disorder. The sample was recruited by convenience, on the day of a medical appointment, from a universe of 300 patients treated at the Bipolar Disorder Program (PROTAHBI) of Hospital de Clínicas de Porto Alegre, Brazil. Selected individuals agreed to participate in the study and signed informed consent forms approved by the institutional ethics committee.

Inclusion criteria involved having a bipolar I disorder diagnosis per the Structured Clinical Interview for DSM-IV, Axis I, Portuguese version (SCID-I) and being currently on treatment. The exclusion criteria were having a diagnosis of mental retardation or dementia, having autoimmune, inflammatory, or infectious diseases (e.g., rheumatic conditions, AIDS, diabetes), current use of medications that might interfere with the immune response, drug abuse/ use of psychoactive substances, and pregnancy/lactation.

\section{Instruments}

Psychiatric evaluation included the SCID-I for BD diagnosis, ${ }^{30}$ Clinical Global Impression for Bipolar Disorder scale (CGI-BP), ${ }^{31}$ Young Mania Rating Scale (YMRS) for manic symptoms, ${ }^{32}$ Hamilton Depression Rating Scale (HAM-D-17) for depressive symptoms, ${ }^{33}$ Functioning Assessment Short Test (FAST) for functional assessment, ${ }^{34}$ and a protocol of clinical and sociodemographic variables.

\section{Coronary calcium scan acquisition and analysis}

All computed tomography (CT) studies for coronary calcium scoring were performed using a 64-row multidetector CT scanner (Aquilion 64 CXL; Toshiba Medical Systems, Otawara, Japan), in a standard fashion (SCCT guideline). ${ }^{35} \mathrm{CCS}$ acquisitions were performed using prospective electrocardiographic triggering, a tube potential of $120 \mathrm{kVp}$ and a weight-adapted tube current-time product (250-300 mAs), covering from carina to below the heart in end-inspiration. Images were reconstructed with a slice thickness of $3 \mathrm{~mm}$ and using conventional filtered back projection. The dose-length product of each CCS acquisition was recorded. Reconstructed images were reviewed and post-processed in a dedicated cardiac workstation (Vitrea; Vital Images, Minnetonka, USA) by an experienced and board-certified cardiac imaging specialist (FST), blinded to patient clinical information. The Agatston method ${ }^{36}$ was used to quantify coronary calcification, and results were compared to the MESA (MultiEthnic Study of Atherosclerosis) database (https://www. mesa-nhlbi.org/Calcium/input.aspx).

\section{Data analysis}

Patients were categorized into two groups according to CCS: a CCS-negative group $(C C S=0)$ and a CCSpositive group (CCS $>0$ ). Comparison of variables between the two study groups relied on analysis of variance (ANOVA) for continuous variables and the Pearson chi-square or Fisher exact test for categorical variables. A Poisson regression analysis was performed to evaluate the association between CCS and count variables. Statistical analyses were performed using SPSS version 21.0. A significance level of 0.05 was adopted for all statistical comparisons.

\section{Ethical aspects}

This study was approved by the ethics committee of Hospital de Clínicas de Porto Alegre (opinion number 13-0049). All participants provided written informed consent. Throughout the process, the right to discontinue participation in the project was assured. Participants were informed about the characteristics of the scan, including radiation exposure and non-use of contrast media during CT. Results were made available in the patient's chart for consultation by the care team; if the CCS was 400 of higher, the patient's doctor was notified and the patient was referred to the appropriate health facility.

\section{Results}

The study sample was composed of 41 patients with BD. Most participants were female $(58.5 \%)$, white $(75.6 \%)$, and married (51.2\%). Demographic characteristics and a detailed description of CVR and psychiatric factors can be found in Table 1 . Ten patients $(24.4 \%)$ had a positive CCS. Clinical variables such as hypertension, diabetes mellitus, dyslipidemia, body mass index, abdominal circumference, and active smoking were not significantly different between CCS-positive and CCS-negative subjects.

The mean age of the entire sample was 46.1 years (standard deviation [SD] 10.3). Patients in the CCSpositive group were older (55.2 years; SD 4.2) than patients in the CCS-negative group (43.1 years; SD 10.0) $(p=0.001)$. 
Table 1 Demographic, cardiovascular risk, and psychiatric factors

\begin{tabular}{|c|c|c|c|c|}
\hline Variables & All patients $(n=41)$ & CCS-negative $(n=31)$ & CCS-positive $(n=10)$ & $\mathrm{p}$-value \\
\hline \multicolumn{5}{|l|}{ Demographic factors } \\
\hline Age, years & $46.1 \pm 10.3$ & $43.1 \pm 10.0$ & $55.2 \pm 4.2$ & 0.001 \\
\hline Male gender & $17(41.5)$ & $13(41.9)$ & $4(40.0)$ & 0.91 \\
\hline \multicolumn{5}{|l|}{ Ethnicity } \\
\hline White & $31(75.6)$ & $23(74.1)$ & $8(80.0)$ & \multirow[t]{2}{*}{0.82} \\
\hline Nonwhite & $9(21.9)$ & $7(22.5)$ & $2(20.0)$ & \\
\hline \multicolumn{5}{|l|}{ Marital status } \\
\hline Single & $16(39.0)$ & $12(38.7)$ & $4(40.0)$ & \multirow[t]{4}{*}{0.44} \\
\hline Married & $21(51.2)$ & $16(51.6)$ & $5(50.0)$ & \\
\hline Divorced & $3(7.3)$ & $2(6.4)$ & $1(10.0)$ & \\
\hline Widowed & $1(2.4)$ & $1(3.2)$ & $0(0)$ & \\
\hline Years of education & $9.9 \pm 3.2$ & $10.4 \pm 2.9$ & $8.3 \pm 3.6$ & 0.08 \\
\hline \multicolumn{5}{|l|}{ Occupation } \\
\hline Student & $1(2.4)$ & $1(3.2)$ & $0(0)$ & \multirow{7}{*}{0.26} \\
\hline Employed & $4(9.8)$ & $4(12.9)$ & $0(0)$ & \\
\hline Unemployed & $5(12.2)$ & $5(16.1)$ & $0(0)$ & \\
\hline Housewife & $1(2.4)$ & $0(0)$ & $1(10.0)$ & \\
\hline Social security benefits & $13(31.7)$ & $12(38.7)$ & $1(10.0)$ & \\
\hline Retired due to disability & $16(39)$ & $8(25.8)$ & $8(80.0)$ & \\
\hline Retired due to service time & $1(2.4)$ & $1(3.2)$ & $0(0)$ & \\
\hline \multicolumn{5}{|l|}{ Cardiovascular risk factors } \\
\hline Hypertension & $11(26.8)$ & $6(19.3)$ & $5(50.0)$ & 0.06 \\
\hline \multicolumn{5}{|l|}{ Diabetes mellitus } \\
\hline Type 1 & $1(2.4)$ & $1(3.2)$ & $0(0)$ & \multirow[t]{2}{*}{0.08} \\
\hline Type 2 & $7(17.0)$ & $3(9.6)$ & $4(40.0)$ & \\
\hline Dyslipidemia & $3(7.3)$ & $3(9.6)$ & $0(0)$ & 0.29 \\
\hline Abdominal circumference & $101.8 \pm 14.2$ & $101.8 \pm 14.9$ & $101.8 \pm 11.0$ & 0.99 \\
\hline $\mathrm{BMI}$ & $29.5 \pm 6.9$ & $30.0 \pm 7.1$ & $28.2 \pm 6.2$ & 0.48 \\
\hline Active smoking & $12(29.3)$ & $10(32.3)$ & $2(20)$ & 0.45 \\
\hline \multicolumn{5}{|l|}{ Psychiatric factors } \\
\hline Number of previous psychiatric hospitalizations & $3.1 \pm 2.8$ & $2.6 \pm 2.5$ & $4.7 \pm 3.0$ & 0.04 \\
\hline Number of manic episodes & $4.4 \pm 4.1$ & $4.2 \pm 4.3$ & $5.2 \pm 3.6$ & 0.55 \\
\hline Number of previous depressive episodes & $8.0 \pm 7.4$ & $7.1 \pm 7.2$ & $10.4 \pm 7.7$ & 0.26 \\
\hline Number of previous suicide attempts & $1.4 \pm 1.6$ & $1.2 \pm 1.5$ & $1.9 \pm 2.0$ & 0.31 \\
\hline Presence of psychotic symptoms & $26(63.4)$ & $21(67.7)$ & $5(50.0)$ & 0.50 \\
\hline FAST & $32.0 \pm 13.2$ & $33.2 \pm 14.3$ & $28.4 \pm 9.0$ & 0.32 \\
\hline \multicolumn{5}{|l|}{ Pharmacological treatment } \\
\hline Lithium & $17(41.4)$ & $12(38.7)$ & $5(50)$ & 0.52 \\
\hline Valproic acid & $22(53.6)$ & $17(54.8)$ & $5(50)$ & 0.79 \\
\hline Antipsychotics & $33(80.4)$ & $26(83.8)$ & $7(70)$ & 0.33 \\
\hline Antidepressants & $15(36.5)$ & $10(32.2)$ & $5(50)$ & 0.31 \\
\hline Anticonvulsants & $3(7.31)$ & $1(3.22)$ & $2(20)$ & 0.07 \\
\hline Benzodiazepines & $12(29.2)$ & $6(19.3)$ & $6(60)$ & 0.01 \\
\hline
\end{tabular}

Data presented as $\mathrm{n}(\%)$ or mean \pm standard deviation.

Bold font indicates statistical significance.

$\mathrm{BMI}$ = body mass index; CCS = coronary calcium score; FAST = Functioning Assessment Short Test.

Regarding psychiatric variables, the mean number of previous psychiatric hospitalizations in the study population was 3.1 (SD 2.8). The mean number of previous psychiatric hospitalizations in CCS-positive patients was higher compared to that of CCS-negative patients $(4.7$ [SD 3.0] vs. 2.6 [SD 2.5], $p=0.04$ ). There was also a positive association between CCS and number of previous psychiatric hospitalizations across the entire study sample $(p<0.001)$ (Figure 1). The number of manic and depressive episodes, number of suicide attempts, and history of psychotic symptoms were not statistically different between the two groups. The use of medications was not statistically different between groups, except for use of benzodiazepines (19.3\% in CCS-negative vs. $60 \%$ in CCS-positive subjects; $\mathrm{p}<0.01)$. In the CCS-positive group, all subjects were in calcium score percentile $>75$, obtained using the MESA calcium calculator (https://www.mesa-nhlbi.org/Calcium/ input.aspx) (Table 2). 


\section{Discussion}

Our study assessed the frequency of a positive CCS in a sample of outpatients with BD type 1, as well as clinical factors associated with a positive score. Patients with a positive CCS were older and had a higher number of previous hospitalizations for mood episodes.

Coronary atherosclerosis is a multifactorial process that eventually leads to coronary obstruction or abrupt plaque rupture and acute coronary events. The process usually starts with the deposition of lipids and smooth muscle cells in the vessel wall, along with inflammatory infiltration. ${ }^{37,38}$ Endothelial dysfunction, thickening of the vessel wall, and continued inflammatory changes within the intimal layer lead to atherosclerotic plaque formation, coronary remodeling, and, eventually, encroachment into the vessel lumen. ${ }^{37,38}$ These processes are influenced by multiple genetic and environmental modifiers, and several clinical risk factors for coronary artery disease (CAD) have been established, including age, sex, cigarette smoking, sedentary lifestyle, diabetes, dyslipidemia, and hypertension. Inflammation is considered a cornerstone in the atherosclerotic process. ${ }^{37}$

Regarding risk factors in Brazilian populations, in a cross-sectional study conducted by the Brazilian Bipolar Disorder Research Network which evaluated CVR factors

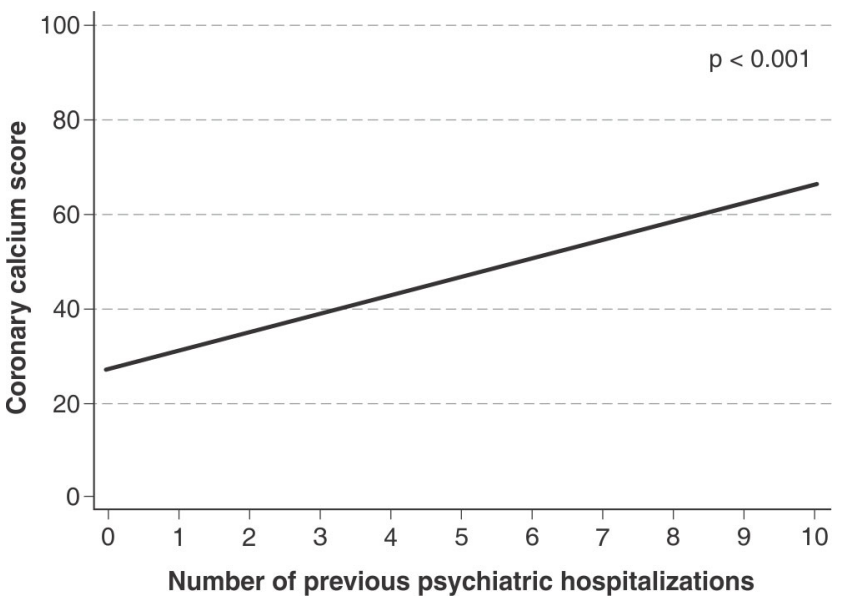

Figure $1 \mathrm{CCS}$ and number of previous psychiatric hospitalizations. CCS = coronary calcium score. among patients with $\mathrm{BD}$, high rates of smoking $(27 \%)$, physical inactivity (64.9\%), alcohol use disorders (20.8\%), elevated fasting glucose $(26.4 \%)$, diabetes (13.2\%), hypertension (38.4\%), hypertriglyceridemia (25.8\%), low HDLcholesterol $(27.7 \%)$, and general $(38.4 \%)$ and abdominal obesity $(59.1 \%)$ were found. ${ }^{39}$

Noninvasive evaluation of CAD has changed dramatically with the advent of coronary calcium scoring. Multiple large, population-based studies have established CCS as the most powerful predictor of cardiovascular events, above and beyond traditional risk factors. ${ }^{29}$ CCS has outperformed clinical risk factors ${ }^{40}$ and other noninvasive modalities in CVR assessment. ${ }^{41-43}$ Individuals with no coronary calcification ( $C C S=0)$, on the other hand, have an excellent prognosis, with an exceedingly low incidence of cardiovascular events for up to 15 years. ${ }^{44}$ Therefore, CCS has the ability to reclassify individual CVR, directly changing pharmacological and preventive measures. The ability to detect CAD noninvasively, in rapid and reproducible fashion, makes CCS an excellent measure of in vivo atherosclerotic disease.

CCS is strongly associated with age, independently of other CVR factors. In our study, patients with a positive CCS were older in comparison to patients with no detectable coronary calcium, an expected phenomenon based on large-scale studies of healthy individuals. Nonetheless, all individuals with a positive CCS (100\%) were found to be in the high CVR stratum (CCS percentile > $75),{ }^{25}$ which would be unlikely to be related to an isolated effect of aging. This finding illustrates a higher atherosclerotic risk in the sample (Table 2).

In the present study, $75.6 \%$ of patients, despite having different traditional CVR profiles and different durations and numbers of BD exacerbations, had a CCS of 0 . The absence of calcified plaques in the coronary arteries would translate to an excellent prognosis regarding incident cardiovascular events for several years. It is unknown, however, which individuals with BD will be more prone to experience a hard CV event even without calcified coronary plaques as detected by CCS. In individuals with $\mathrm{BD}$, besides the increased prevalence of traditional CVR factors, the younger age and pro-inflammatory changes related to the disease itself may be associated with noncalcified plaques, although this hypothesis requires confirmation. CCS does not detect non-calcified plaque and

\begin{tabular}{|c|c|c|c|c|c|c|}
\hline Patients & Gender & Age (years) & Ethnicity & CCS (Agatston) & MESA estimate CCS-positive (\%) & MESA percentile \\
\hline 1 & $\mathrm{~F}$ & 59 & W & 45 & 34 & 85 \\
\hline 2 & M & 55 & W & 112 & 56 & 81 \\
\hline 3 & $\mathrm{~F}$ & 55 & W & 174 & 26 & 97 \\
\hline 4 & $\mathrm{~F}$ & 45 & W & 1 & 7 & 93 \\
\hline 5 & M & 60 & NW & 94 & 46 & 83 \\
\hline 6 & $\mathrm{~F}$ & 56 & W & 703 & 28 & 99 \\
\hline 7 & M & 55 & W & 366 & 56 & 94 \\
\hline 8 & $\mathrm{~F}$ & 58 & NW & 8 & 25 & 80 \\
\hline 9 & $\mathrm{~F}$ & 57 & W & 25 & 30 & 84 \\
\hline 10 & M & 52 & W & 77 & 47 & 82 \\
\hline
\end{tabular}

* https://www.mesa-nhlbi.org/Calcium/input.aspx

$\mathrm{CCS}=$ coronary calcium score; $\mathrm{F}=$ female; $\mathrm{M}=$ male; MESA = Multi-Ethnic Study of Atherosclerosis; $\mathrm{NW}=$ nonwhite; $\mathrm{W}=$ white. 
may not capture the true spectrum of CVR in patients with BD. Further long-term studies with larger sample sizes are necessary to test this hypothesis.

$\mathrm{BD}$ is linked to a pro-inflammatory state, which is exacerbated in manic and depressive episodes. The number and frequency of manic/depressive episodes imposes a chronic and cumulative inflammatory burden over the years. ${ }^{45}$ We observed that $24.3 \%$ of participants in our sample study were CCS-positive. These individuals had higher numbers of previous psychiatric hospitalizations. Our hypothesis is that patients who are more severely ill, at advanced stages, and with more exacerbations of mood episodes experience a higher inflammatory burden. This, together with the risk factors already described and which probably increase with disease progression, would lead to a potentiation of the atherosclerotic process and consequent increase in CVR. Considering the evidence linking accelerated atherosclerosis in young patients with mood disorders ${ }^{20}$ and the increased incidence of $\mathrm{CV}$ events in patients with $\mathrm{BD}$, a possible link between $\mathrm{BD}$ stage and coronary atherosclerosis can be postulated.

One limitation of the present study is its crosssectional design. Due to methodological issues, we did not have access to the lipid profile of participants, which might have enriched our analysis of the results. Furthermore, our limited sample size may have underpowered our ability to detect eventual associations between CCS and other variables, as well as to control for potential confounders.

On the other hand, our study has several strengths. This was the first study to evaluate CCS in a sample of patients with BD. The correlation between positive CCS and number of psychiatric hospitalizations suggests an association between severity of BD and alterations in coronary calcium load, offering an important perspective regarding cardiovascular evaluation and adequate treatment in BD. Although the literature supports cardiovascular disease as the leading death cause in bipolar patients, there is still a lack of studies focused on the best method for diagnosis and stratification of CVR in this population. As it is widely known, patients with BD do not necessarily correspond to the general profile of the population, and consequently may benefit from other specific approaches. CCS may be a potential method for diagnosis and stratification of CVR in BD patients, but further research on the subject is required.

\section{Acknowledgements}

The authors would like to thank the Graduate Program in Psychiatry at Universidade Federal do Rio Grande do Sul (UFRGS). This work was supported by Fundo de Incentivo a Pesquisa e Eventos (FIPE-HCPA).

\section{Disclosure}

CSG has been a paid consultant/speaker for Actelion, Janssen-Cilag, and Lundbeck. MK has served as consultant/speaker for Daiichi Sankyo. The authors report no conflicts of interest.

\section{References}

1 Munkholm K, Vinberg M, Vedel Kessing L. Cytokines in bipolar disorder: a systematic review and meta-analysis. J Affect Disord. 2013;144:16-27.

2 Munkholm K, Braüner JV, Kessing LV, Vinberg M. Cytokines in bipolar disorder vs. healthy control subjects: a systematic review and meta-analysis. J Psychiatr Res. 2013;47:1119-33.

3 Modabbernia A, Taslimi S, Brietzke E, Ashrafi M. Cytokine alterations in bipolar disorder: a meta-analysis of 30 studies. Biol Psychiatry. 2013;74:15-25.

4 Collins PY, Patel V, Joestl SS, March D, Insel TR, Daar AS, et al. Grand challenges in global mental health. Nature. 2011;475:27-30.

5 Callaghan RC, Khizar A. The incidence of cardiovascular morbidity among patients with bipolar disorder: a population-based longitudinal study in Ontario, Canada. J Affect Disord. 2010;122:118-23.

6 Osby U, Brandt L, Correia N, Ekbom A, Sparén P. Excess mortality in bipolar and unipolar disorder in Sweden. Arch Gen Psychiatry. 2001;58:844-50.

7 Weeke A, Juel K, Vaeth M. Cardiovascular death and manicdepressive psychosis. J Affect Disord. 1987;13:287-92.

8 Goldstein BI, Fagiolini A, Houck P, Kupfe DJ. Cardiovascular disease and hypertension among adults with bipolar I disorder in the United States. Bipolar Disord. 2009;11:657-62.

9 Grant BF, Stinson FS, Hasin DS, Dawson DA, Chou SP, Ruan WJ, et al. Prevalence, correlates, and comorbidity of bipolar I disorder and axis I and II disorders: results from the National Epidemiologic Survey on Alcohol and Related Conditions. J Clin Psychiatry. 2005;66:1205-15.

10 Murray DP, Weiner M, Prabhakar M, Fiedorowicz JG. Mania and mortality: why the excess cardiovascular risk in bipolar disorder? Curr Psychiatry Rep. 2009;11:475-80.

11 Kilbourne AM, Cornelius JR, Han X, Pincus HA, Shad M, Salloum I, et al. Burden of general medical conditions among individuals with bipolar disorder. Bipolar Disord. 2004;6:368-73.

12 Mcintyre RS, Konarski JZ, Misener VL, Kennedy SH. Bipolar disorder and diabetes mellitus: epidemiology, etiology, and treatment implications. Ann Clin Psychiatry. 2005;17:83-93.

13 Fagiolini A, Kupfer DJ, Houck PR, Novick DM, Frank E. Obesity as a correlate of outcome in patients with bipolar I disorder. Am J Psychiatry. 2003;160:112-7.

14 McElroy SL, Frye MA, Suppes T, Dhavale D, Keck PE Jr, Leverich GS, et al. Correlates of overweight and obesity in 644 patients with bipolar disorder. J Clin Psychiatry. 2002;63:207-13.

15 Kilbourne AM, Brar JS, Drayer RA, Xu X, Post EP. Cardiovascular disease and metabolic risk factors in male patients with schizophrenia, schizoaffective disorder, and bipolar disorder. Psychosomatics. 2007;48:412-7.

16 Kilbourne AM, Post EP, Bauer MS, Zeber JE, Copeland LA, Good CB, et al. Therapeutic drug and cardiovascular disease risk monitoring in patients with bipolar disorder. J Affect Disord. 2007; 102:145-51.

17 Cassidy F, Ahearn E, Carroll BJ. Elevated frequency of diabetes mellitus in hospitalized manic-depressive patients. Am J Psychiatry. 1999;156:1417-20.

18 Newcomer JW. Medical risk in patients with bipolar disorder and schizophrenia. J Clin Psychiatry. 2006;67:e16.

19 Kilbourne AM, Rofey DL, McCarthy JF, Post EP, Welsh D, Blow FC. Nutrition and exercise behavior among patients with bipolar disorder. Bipolar Disord. 2007;9:443-52.

20 Goldstein BI, Carnethon MR, Matthews KA, Mclntyre RS, Miller GE, Raghuveer G, et al. Major depressive disorder and bipolar disorder predispose youth to accelerated atherosclerosis and early cardiovascular disease: a scientific statement from the American Heart Association. Circulation. 2015;132:965-86.

21 Arango C, Bobes J, Aranda P, Carmena R, Garcia-Garcia M, Rejas J, et al. A comparison of schizophrenia outpatients treated with antipsychotics with and without metabolic syndrome: findings from the CLAMORS study. Schizophr Res. 2008;104:1-12.

22 Bruggeman R, Schorr SG, Van der Elst K, Postma M, Taxis K. Costeffectiveness of screening for diabetes in a cohort of patients with schizophrenia. Schizophr Res. 2008;102:161-2.

23 Daumit GL, Goff DC, Meyer JM, Davis VG, Nasrallah HA, McEvoy $\mathrm{JP}$, et al. Antipsychotic effects on estimated 10-year coronary heart 
disease risk in the CATIE schizophrenia study. Schizophr Res. 2008:105:175-87.

24 Taxis K, Schorr S, Fouchier M, Slooff C, Bruggeman R. Is it appropriate to use cardiovascular risk scores in patients with psychotic disorders? Schizophr Res. 2008;102:169.

25 Goff DC Jr, Lloyd-Jones DM, Bennett G, Coady S, D'Agostino RB, Gibbons R, et al. 2013 ACC/AHA guideline on the assessment of cardiovascular risk: a report of the American College of Cardiology/ American Heart Association Task Force on Practice Guidelines. Circulation. 2014;129:S49-73.

26 Bischoff B, Kantert C, Meyer T, Hadamitzky M, Martinoff S, Schömig $\mathrm{A}$, et al. Cardiovascular risk assessment based on the quantification of coronary calcium in contrast-enhanced coronary computed tomography angiography. Eur Heart J Cardiovasc Imaging. 2012;13:468-75.

27 Tota-Maharaj R, Blaha MJ, McEvoy JW, Blumenthal RS, Muse ED, Budoff MJ, et al. Coronary artery calcium for the prediction of mortality in young adults $<45$ years old and elderly adults $>75$ years old. Eur Heart J. 2012;33:2955-62.

28 Tota-Maharaj R, Blaha MJ, Blankstein R, Silverman MG, Eng J, Shaw LJ, et al. Association of coronary artery calcium and coronary heart disease events in young and elderly participants in the multiethnic study of atherosclerosis: a secondary analysis of a prospective, population based cohort. Mayo Clin Proc. 2014;89:1350-9.

29 Hecht HS. Coronary artery calcium scanning: past, present, and future. JACC Cardiovasc Imaging. 2015;8:579-96.

30 First MB, Gibbon M, Williams JBW. Structured clinical interview for DSM-IV-TR axis I disorders, research version, patient edition. (SCIDI/P). New York: Biometrics Research; 2002.

31 Spearing MK, Post RM, Leverich GS, Brandt D, Nolen W. Modification of the Clinical Global Impressions (CGI) Scale for use in bipolar illness (BP): the CGI-BP. Psychiatry Res. 1997;73:159-71.

32 Young RC, Biggs JT, Ziegler VE, Meyer DA. A rating scale for mania: reliability, validity and sensitivity. Br J Psychiatry. 1978;133:429-35.

33 Hamilton N. A rating scale for depression. J Neurol Neurosurg Psychiatry. 1960;23:56-62.

34 Rosa AR, Sánchez-Moreno J, Martínez-Aran A, Salamero M, Torrent $C$, Reinares $M$, et al. Validity and reliability of the Functioning Assessment Short Test (FAST) in bipolar disorder. Clin Pract Epidemiol Ment Health. 2007;3:5
35 Halliburton SS, Abbara S, Chen MY, Gentry R, Mahesh M, Raff GL, et al. Society of Cardiovascular Computed Tomography. SCCT guidelines on radiation dose and dose-optimization strategies in cardiovascular CT. J Cardiovasc Comput Tomogr. 2011; 5:198-224

36 Agatston AS, Janowitz WR, Hildner FJ, Zusmer NR, Viamonte M Jr, Detrano R. Quantification of coronary artery calcium using ultrafast computed tomography. J Am Coll Cardiol. 1990;15:827-32.

37 Libby P. Inflammation in atherosclerosis. Arterioscler Thromb Vasc Biol. 2012;32:2045-51.

38 Wong BW, Meredith A, Lin D, McManus BM. The biological role of inflammation in atherosclerosis. Can J Cardiol. 2012;28:631-41.

39 Gomes FA, Almeida KM, Magalhães PV, Caetano SC, KauerSant'Anna M, Lafer B, et al. Cardiovascular risk factors in outpatients with bipolar disorder: a report from the Brazilian research network in bipolar disorder. Rev Bras Psiquiatr. 2013;35:126-30.

40 Detrano R, Guerci AD, Carr JJ, Bild DE, Burke G, Folsom AR, et al. Coronary calcium as a predictor of coronary events in four racial or ethnic groups. N Engl J Med. 2008;358:1336-45.

41 Peters SA, den Ruijter HM, Bots ML, Moons KG. Improvements in risk stratification for the occurrence of cardiovascular disease by imaging subclinical atherosclerosis: a systematic review. Heart. 2012; 98:177-84.

42 Yeboah J, McClelland LR, Polonski TS, Burke GL, Sibley CT, O'Leary D, et al. Comparison of novel risk markers for improvement in cardiovascular risk assessment in intermediate-risk individuals. JAMA. 2012;308:788-95.

43 Blaha MJ, Cainzos-Achirica M, Greenland P, McEvoy JW, Blankstein $\mathrm{R}$, Budoff $\mathrm{MJ}$, et al. Role of coronary artery calcium score of zero and other negative risk markers for cardiovascular disease: the multiethnic study of atherosclerosis (MESA). Circulation. 2016;133: 849-58.

44 Valenti V, Ó Hartaigh B, Heo R, Cho I, Schulman-Marcus J, Gransa $\mathrm{H}$, et al. A 15-year warranty period for asymptomatic individuals without coronary artery calcium: a prospective follow-up of 9,715 individuals. JACC Cardiovasc Imaging. 2015;8:900-9.

45 Kapczinski F, Dias VV, Kauer-Sant'Anna M, Frey BN, Grassi-Oliveira $\mathrm{R}$, Colom $\mathrm{F}$, et al. Clinical implications of a staging model for bipolar disorders. Expert Rev Neurother. 2009;9:957-66. 